\title{
OPTIMALISASI TUGAS PERAWATAN KESEHATAN OLEH KELUARGA SEBAGAI UPAYA MENINGKATKAN KESEHATAN PENDERITA HIPERTENSI DI KELURAHAN SIMPANG TIGA SIPIN
}

\author{
Netha Damayantie \\ Jurusan Keperawatan, Poltekkes Kemenkes Jambi \\ Email:nethafauzi1996@gmail.com,
}

\begin{abstract}
Hypertension is one very serious disease and generally sufferers do not know it has hypertension before checking blood pressure. When hypertension is not treated, it can result in more effects such as heart disease, myocardial infarction, stroke, or renal failure, which ends with death. Early detection and effective hypertension treatment can prevent increased blood pressure and complications. Hypertension control can be done through a family approach. Community service aims to optimize health care tasks by the family as an effort to improve the health status of people with hypertension in Kelurahan Simpang Tiga Sipin Kecamatan Kotabaru 2019. Activities consist of preparation stage, implementation and evaluation. The form of activity is health screening and health education activities involving lecturers and students in nursing department with participants from 56 people. Expected increased family knowledge after counseling. Health counseling through information communication about the optimization of family tasks by using audio visual further strengthens the understanding of the family. Puskesmas Paal V can follow up on results with family approach. Make the family of hypertension patients as assisted families, in collaboration with health promotion programs to conduct education and programs of untransmitted diseases for the control of blood pressure and regular treatment of patients with hypertension.
\end{abstract}

Keywords: education, family task, hypertention

\section{ABSTRACT}

Hipertensi merupakan salah satu penyakit yang sangat serius dan umumnya penderita tidak mengetahui dirinya mengidap hipertensi sebelum memeriksakan tekanan darah. Apabila hipertensi tidak dirawat, bisa mengakibatkan dampak yang lebih seperti penyakit jantung, infark miokardium, stroke, atau gagal ginjal yang berakhir dengan kematian. Deteksi dini dan perawatan hipertensi yang efektif dapat mencegah terjadinya peningkatan tekanan darah dan komplikasi. Bentuk pengendalian hipertensi dapat dilakukan melalui pendekatan keluarga. Pengabdian masyarakat bertujuan untuk optimalisasi tugas perawatan kesehatan oleh keluarga sebagai upaya meningkatkan status kesehatan penderita hipertensi di Kelurahan Simpang Tiga Sipin Kecamatan Kotabaru Tahun 2019. Kegiatan terdiri dari tahap persiapan, pelaksanaan dan evaluasi. Bentuk kegiatan adalah pemeriksaan kesehatan dan Pendidikan kesehatan Kegiatan melibatkan Dosen dan mahasiswa Jurusan Keperawatan dengan peserta 56 orang. Diharapkan adanya peningkatan pengetahuan keluarga sesudah penyuluhan. Penyuluhan kesehatan yang dilakukan melalui komunikasi informasi tentang optimalisasi tugas keluarga dengan menggunakan audio visual semakin memperkuat pemahaman yang ada pada keluarga. Puskesmas Pall Vkota Jambi dapat menindaklanjuti hasil dengan Pendekatan Keluarga (PIS-PK), menjadikan keluarga pasien hipertensi sebagai keluargaa binaan, bekerjasama dengan program promosi kesehatan melakukan edukasi dan program penyakit tidak menular untuk kontrol tekanan darah dan pengobatan yang teratur pada penderita hipertensi

Kata Kunci; hipertensi, pendidikan, tugas keluarga

\section{PENDAHULUAN}

Penyakit hipertensi merupakan salah

satu penyakit yang sangat serius dan dikategorikan sebagai penyakit yang dapat membunuh seseorang secara diam-diam karena pada umumnya penderita tidak 
mengetahui dirinya mengidap hipertensi sebelum memeriksakan tekanan darahnya. Hipertensi atau tekanan darah tinggi adalah suatu peningkatan abnormal tekanan darah dalam pembuluh darah arteri secara terusmenerus lebih dari suatu periode. Hipertensi juga didefinisikan sebagai tekanan darah sistolik lebih dari $140 \mathrm{mmHg}$ dan tekanan darah diastolik lebih dari $90 \mathrm{mmHg}$ yang terjadi pada seorang klien ( Joint National Committee on Prevention, Detection, Evaluation and Treatment of High Blood Pressure (2003, dalam Wallace 2008).

Hipertensi di perkirakan akan meningkat dari tahun ke tahun, hal ini disebabkan karena adanya perubahan gaya hidup, mengkonsumsi makanan tinggi lemak, kolesterol, merokok dan stres yang tinggi (Smeltzer dan Bare, 2002). Pada tahun 2025 yang akan datang, jumlah penderita hipertensi diprediksi akan meningkat menjadi 29\%, atau sekitar 1,6 miliar orang di seluruh dunia (Tedjakusuma, 2012). Di Indonesia Hipertensi merupakan masalah yang terus meningkat. Prevalensi hipertensi di Indonesia usia diatas 18 tahun sebesar $31,7 \%$ dengan komplikasi penyakit kardiovaskuler lebih banyak pada perempuan $52 \%$ dibandingkan laki-laki $48 \%$.

Perjalanan penyakit hipertensi sangat perlahan, penderita hipertensi mungkin tak menunjukan gejala awal dan baru terasa setelah bertahun-tahun. Apabila hipertensi tidak dirawat, bisa mengakibatkan dampak yang lebih buruk dari penyakit sebelumnya seperti penyakit jantung, infark miokardium, stroke, atau gagal ginjal yang berakhir dengan kematian. Namun deteksi dini dan perawatan hipertensi yang efektif dapat mencegah terjadinya peningkatan tekanan darah dan komplikasi (Price \& Wilson, 2006).

Salah satu bentuk upaya pengendalian penyakit hipertensi dapat dilakukan dengan pendekatan keluarga. Kemenkes (2016) dalam pedoman Indonesia sehat berbasis keluarga menyatakan bahwa salah satu penyakit tidak menular yang cukup penting dalam Pendekatan keluarga adalah hipertensi (tekanan darah tinggi). Prevalensi hipertensi pada orang dewasa menurut Riskesdas tahun 2013 adalah $25,8 \%$ atau sama dengan 42,1 juta jiwa. Dari sejumlah itu baru $36,8 \%$ yang telah kontak dengan petugas kesehatan, sementara sisanya sekitar 2/3 tidak tahu kalau dirinya menderita hipertensi, hal ini menunjukkan bahwa bila tidak menggunakan pendekatan keluarga, $2 / 3$ bagian atau sekitar 28 juta penderita hipertensi tidak akan tertangani. Berdasarkan kondisi yang dipaparkan menunjukkan bahwa pendekatan keluarga mutlak harus dilakukan bila kita ingin pengendalian penyakit hipertensi berhasil dalam upaya pembangunan kesehatan.

Keluarga merupakan faktor utama pembentuk gaya hidup positif anggotanya (Stanhope \& Lancaster, 2010). Keluarga adalah faktor penentu keberhasilan dalam penanaman perilaku hidup sehat bagi keluarganya. Keluarga yang tidak menerapkan dan memperkenalkan perilaku hidup sehat sejak dini akan berisiko mempunyai masalah kesehatan lebih besar dibandingkan keluarga yang mampu menerapkan perilaku hidup sehat sejak dini (Friedman, 2003). Fungsi utama keluarga salah satu diantaranya adalah fungsi perawatan keluarga, dimana keluarga melaksanakan tugas perawatan kesehatan yang bersifat preventif dan secara bersamasama merawat anggota keluarga yang sakit. Kesanggupan keluarga melaksanakan perawatan atau pemeliharaan kesehatan dapat dilihat dari tugas kesehatan keluarga yang dilaksanakan (Mubarak, Chayatin, \& Santoso, 2010). Tugas perawatan kesehatan keluarga memberi peluang 12.03 kali dalam meningkatkan status kesehatan pada agregate masyarakat dengan kelompok 
lansia dengan hipertensi menjadi lebih baik jika dibandingkan dengan keluarga yang tidak melakukan tugas perawatan kesehatan keluarga dengan baik. Kurangnya pengetahuan keluarga khususnya mengenai tugas kesehatan keluarga dapat berakibat tidak tepatnya penanganan yang diberikan kepada anggota keluarga yang sakit. Hasil penelitian menunjukkan di Kecamatan Jetis kota Yogyakarta terdapat 49,7\% keluarga belum mampu mengenal masalah kesehatan dan $36,2 \%$ belum mampu mengambil keputusan terhadap masalah kesehatan yang dialami (Amigo, 2012)

Puskesmas Paal V merupakan salah satu Puskesmas yang terdapat di kota Jambi yang melaksanakan Penyelenggaraan Upaya kesehatan tingkat pertama untuk memelihara dan meningkatkan kesehatan serta mencegah dan menanggulangi timbulnya masalah kesehatan dengan sasaran keluarga, kelompok, dan masyarakat. Berdasarkan hasil pencatatan dan pelaporan Dinas Kesehatan Kota Jambi Tahun 2017 diketahui untuk penyakit hipertensi Puskesmas Pall V memiliki kasus hipertensi terbesar 588 orang, meningkat menjadi 1151 penderita hipertensi artinya terjadi peningkatan kasus dari tahun 2017 ke tahun 2018. Prevalensi hipertensi pada orang dewasa yang cenderung meningkat memerlukan upaya pengendalian berupa keterlibatan keluarga dalam berbagai aspek penunjang kesehatan penderita hipertensi melalui kemampuan keluarga dalam mengenal masalah hipertensi, merawat penderita hipertensi, mengambil keputusan tindakan yang tepat, modifikasi lingkungan yang sehat serta memanfaatkan sarana kesehatan yang dikenal dengan tugas perawatan kesehatan keluarga. Perawat mempunyai peran sebagai pendidik dan koordinator pelayanan kesehatan, melalui peran ini perawat mampu mengoptimalkan peran keluarga dalam menyediakan sumbersumber yang penting untuk memberikan pelayanan kesehatan/keperawatan bagi individu sendiri dan orang lain dalam keluarga.

Pengabdian masyarakat ini bertujuan untuk optimalisasi tugas perawatan kesehatan oleh keluarga sebagai upaya meningkatkan status kesehatan penderita hipertensi di Kelurahan Simpang Tiga Sipin Kecamatan Kotabaru Tahun 2019. Masyarakat yang diharapkan antara lain : Mengoptimalkan upaya kesehatan berbasis masyarakat sebagai salah satu bentuk pelayanan kesehatan di Puskesmas melalui upaya pembinaan kesehatan keluarga, dapat meningkatkan peran perawat komunitas di Puskesmas Pall V dalam Program Indonesia Ssehat dengan Pendekatan Keluarga (PIS-PK) dan dapat meningkatkan peran dan keterlibatan keluarga dalam perawatan penderita hipertensi dalam upaya peningkatan penatalaksanaan perawatan Hipertensi dirumah,

\section{TARGET DAN LUARAN}

Target capaian adalah 60 orang keluarga pasien hipertensi dan yang beresiko menderita hipertensi di RT 05, 06, 09 dan RT 37 Kelurahan Simpang Tiga Sipin. Luaran dari kegiatan Program Kemitraan Masyarakat ini adalah adanya meningkatnya pengetahuan keluarga tentang tugas perawatan pada penderita hipertensi, diketahuinya kadar kolesterol darah dan tekanan darah pada anggota keluarga yang beresiko atau menderita hipertensi dan publikasi hasil pengabdian masyarakat.

\section{METODE PELAKSANAAN}

Kegiatan dibagi dalam tiga tahapan yaitu persiapan, pelaksanaan dan evaluasi yang dapat dijabarkan sebagai berikut :

a. Tahap Persiapan

Kegiatan pengabdian masyarakat dilaksanakan pada bulan Juli sampai dengan Agustus 2019 dengan uraian kegiatan : pada tanggal 22 Mei 2019 
dilakukan survey awal, identifikasi data penduduk dan masalah kesehatan yang ada di wilayah kerja Kelurahan Simpang Tiga Sipin. Tanggal 18 Juni dosen berkoordinasi dengan sekretaris lurah Simpang Tiga Sipin tentang sasaran dan tempat pelaksanaan kegiatan yaitu di Mesjid Al Hilal. Tanggal 28 -29 Juni dosen melakukan kunjungan rumah pada keluarga dengan penderita hipertensi di RT 05 dan 06, berlanjut kerumah keluarga lain yang mempunyai penderita hipertensi ataupun yang beresiko yang dilanjutkan dengan kegiatan yang sama pada tanggal 05 - 06 Juli di RT 09 dan 37. Persiapan sarana dan prasarana dilakukan tanggal 10Juli 2019. Kegiatan penyuluhan dilaksanakan pada tanggal 11 Juli 2019 dan Evaluasi akhir kegiatan dan terminasi dilaksanakan tanggal 15 Juli 2019.

b. Tahap pelaksanaan

1) Kegiatan dilaksanakan pada pada hari kamis tanggal 11 Juli 2019 jam 14.00 sampai dengan 16.30 WIB di Mesjid Al Hilal Kelurahan Simpang Tiga Sipin Jambi. Memilihan lokasi karena terletak diantara RT 05, 06, 09 dan RT 37 dimana sasaran pengabdian masyarakat berdomisili. Kegiatan dihadiri oleh 56 orang. kegiatan diawali dengan pengukuran tekanan darah dan kadar kolesterol darah mereka.

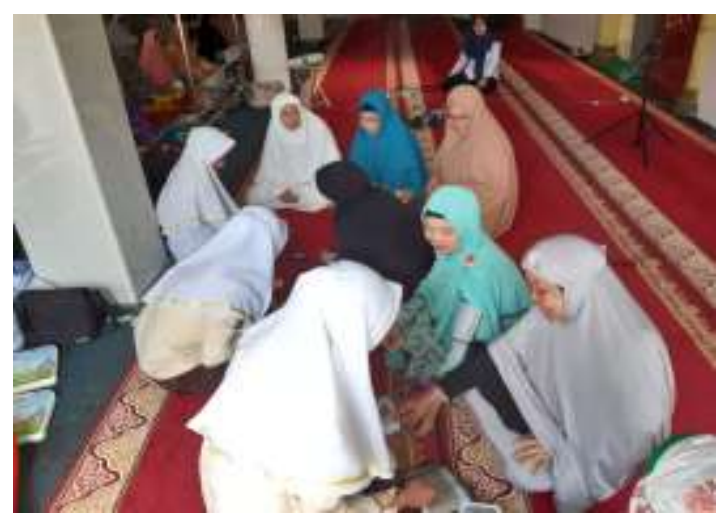

Gambar 1. Proses Pengukuran Tekanan Darah
Pemeriksaan bertujuan untuk mengukur kadar kolesterol dalam darah. Hasil pemeriksaan menunjukkan 59 ibu-ibu yang dilakukan pengukuran, $41 \%$ Tekanan darah $\geq 140$ mmhg dan $47 \%$ kolesterol darah $\geq 200 \mathrm{mg} / \mathrm{dl}$

2) Kegiatan penyuluhan diawali dengan apersepsi untuk pengetahui pengetahuan keluarga tentang Hiperteni dan bagaimana peran keluarga dalam merawat anggota. Hasil apersepsi diketahui 2 orang menyatakan hipertensi adalah peningkatan tekanan darah diatas 140 mmHg, kegemukan dan makan makanan yang asin penyebab tekanan darah tinggi, serta sulit bagi mereka mengubah pola makan suami yang menyukai makanan bersantan. Keluarga penderita hipertensi jarang membawa keluarganya ke Puskesmas untuk kontrol karena merasa tidak ada keluhan, susah mencegah semua yang suka makanan bersantan serta kebiasaan makan gorengan.

Upaya meningkatkan kemampuan mengenal hipertensi dan penatalaksanaan dilakukan dengan memberikan penyuluhan. Materi yang disampaikan meliputi pengertian hipertensi, penyebab hipertensi, faktor resiko terjadinya hipertensi, tanda dan gejala hipertensi, komplikasi hipertensi serta penatalaksanaan hipertensi. Kepada keluarga juga disampaikan peran keluarga dalam merawat anggota keluarga dengan hipertensi berupa Agar keluarga lebih memahami materi yang diberikan, dosen memutarkan video tentang hipertensi dan penatalaksanaanya Penyampaian yang menarik dengan pemutaran video singkat ini membuat peserta lebih antusias, tidak bosan dan 
tetap mengikuti kegiatan sampai akhir.

\section{HASIL DAN PEMBAHASAN}

Kegiatan pemeriksaan dan penyuluhan dilaksanakan pada pada hari kamis tanggal 11 Juli 2019 jam 14.00 sampai dengan 16.30 WIB di Mesjid Al Hilal Kelurahan Simpang Tiga Sipin Jambi. Kepada peserta yang sudah hadir dilakukan pengkuran tekanan darah dan kolesterol darah oleh dosen dibantu mahasiswa. Selama pemeriksaan terjadi diskusi dengan peserta seperti pertanyaan mengapa kolesterol mereka bisa tinggi, peserta yang berpuasa saat ini kolesterol darahnya normal, keluhan sulit untuk menjaga makanan dari santan dan gorengan. Hasil pemeriksaan didapatkan dari 59 peserta 23 orang tekanan darah $\geq$ 140/90 mmhg (54\%) dan 26 orang kolesterol lebih dari $200 \mathrm{mg} / \mathrm{d}(39 \%)$ seperti pada diagram di bawah ini :

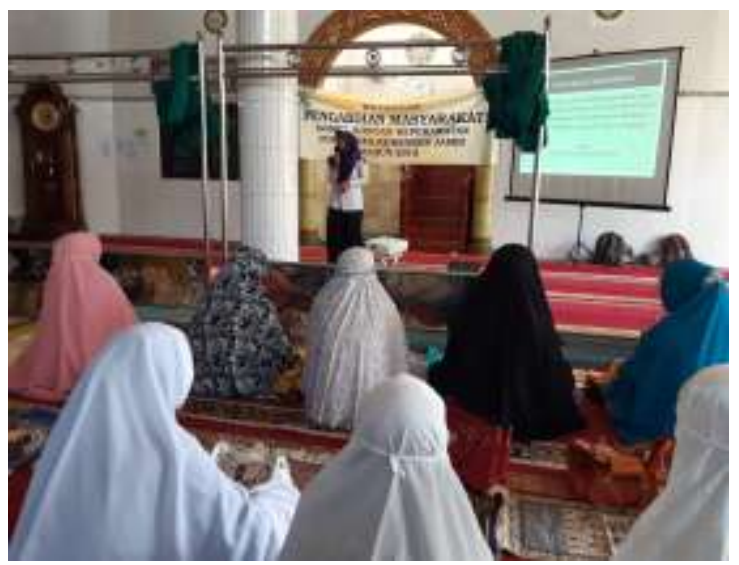

Gambar 2. Penyuluhan dalam Kegiatan Pengabdian Masyarakat

Pada saat penyuluhan dosen mengekslorasi pengetahuan peserta tentang apa itu hipertensi, mengapa seseorang bisa menderita hipertensi secara lisan. Edukasi tentang tugas keluarga dalam memelihara dan meningklatkan status kesehatan penderita ataupun yang beresiko menderita hipertansi meliputi pengertian hipertensi, faktor resiko penyebab hipertensi, upaya penatalaksanaan hipertensi, tugas keluarga dalam merawat penderita atau yang beresiko hipertensi. Pada sesi diskusi peserta mengajukan pertanyaan antara lain tentang : Apakah penyakit hipetensi bisa sembuh?, Bagaimana dengan kebiasaan mereka makan obat jika tekanan darah tinggi dan kepala pusing saja ?, Bagaimana cara keluarga merubah kebiasaan makan penderita hipertensi yang tidak sehat seperti suka makanan bersantan, makan gorengan saat sarapan atau sore hari.

Setelah pemeriksaan, penyuluhan dan diskusi selesai, peserta diberikan pertanyaan untuk mengetahui perubaham pengetahuan mereka setelah diberikan penyuluhan, yaitu :

1. Pengertian hipertensi, salah seorang ibu mengatakan hipertensi adalah penyakit dimana tekanan darah lebih dari 140/90 $\mathrm{mmHg}$.

2. Dampak atau komplikasi hipertensi, peserta hanya mengetahui komplikasi hipertensi adalah stroke dan penyakit jantung lainnya.

3. Apa yang bisa dilakukan keluarga dalam merawat anggota keluarga dengan penyakit hipertensi, salah satu ibu berpendapat yaitu mengenali tanda-tanda hipertensi, menciptakan lingkungan yang sehat dengan mengatur makanan, menghindari berat badan berlebih, hindari rokok terutama baik aktif maupun pasif, rajin berolahraga dan menghindari stress jika ada masalah.

Undang-undang Nomor 12 Tahun 2012 tentang Pendidikan Tinggi Pasal 47 menegaskan (1) bahwa Pengabdian kepada Masyarakat merupakan kegiatan Civitas Akademika dalam mengamalkan dan membudayakan Ilmu Pengetahuan dan Teknologi untuk memajukan kesejahteraan umum dan mencerdaskan kehidupan bangsa; (2) Pengabdian kepada Masyarakat sebagaimana dimaksud pada ayat (1) dilakukan dalam berbagai bentuk kegiatan sesuai dengan budaya akademik, keahlian, 
dan/atau otonomi keilmuan Civitas Akademika serta kondisi sosial budaya masyarakat. Pengabdian kepada masyarakat yang dilakukan oleh dosen di Kelurahan Simpang Tiga Sipin Kota Jambi berupa optimalisasi tugas perawatan kesehatan oleh keluarga sebagai upaya meningkatkan status kesehatan penderita hipertensi, dimana dosen bekerjasama dengan pihak kelurahan Simpang Tiga Sipin melakukan upaya promotif-educative melalui kegiatan pengabdian masyarakat dosen Jurusan Keperawatan Poltekkes Jambi.

Sebelum dilakukan penyuluhan dosen melakukan apersepsi, 2 peserta menyatakan hipertensi adalah peningkatan tekanan darah diatas $140 \mathrm{mmHg}$, menurut mereka penyebab hipertensi adalah kegemukan dan makan makanan yang asin sehingga meningkatkan tekanan darah. Hasil ini sejalan dengan pendapat Notoatmodjo (2010), Pengetahuan (knowledge) adalah hasil penginderaan manusia, atau hasil tahu seseorang terhadap objek melalui indera yang dimilikinya (mata, hidung, telinga, dan sebagainya). Dengan sendirinya, pada waktu penginderaan sampai menghasilkan pengetahuan tersebut sangat dipengaruhi oleh intensitas perhatian dan persepsi terhadap objek. Pendapat keluarga yang belum tepat tentang penyebab hipertensi dapat disebabkan kurangnya informasi yang diperoleh keluarga bahwa hipertensi dapat disebabkan oleh Hipertensi primer juga disebut hipertensi esensial yang disebabkan faktor Gen, perubahan fisi dan lingkungan. Penyebab kedua adalah Hipertensi sekunder sering terjadi dengan cepat dan bisa menjadi lebih parah daripada hipertensi primer yang disebabkan diantaranya penyakit ginjal, masalah dengan tiroid.

Pengetahuan tentang hipertensi dan upaya pengendalian hipertensi secara nyata menunjukkan pengaruhnya terhadap upaya pengendalian hipertensi. Hal ini sesuai dengan pendapat Maryono (2009) bahwa pengetahuan yang baik akan mampu merubah gaya hidup dengan cara berhenti merokok sedini mungkin, berolahraga secara teratur, perbaikan diet, hindari stres serta hindari pola hidup tidak sehat. semakin baik pengetahuan responden mengenai hipertensi maka semakin baik pula upaya responden untuk mengendalikan hipertensi yang dideritanya. Setelah diberikan penyuluhan peserta mampu menjawab evaluasi tentang pengertian hipertensi, dampak atau komplikasi dari hipertensi dan tugas keluarga dalam merawat anggota keluarga dengan hipertensi

Pada saat diskusi didapatkan informasi dari keluarga bahwa Keluarga penderita hipertensi jarang membawa keluarganya ke Puskesmas untuk kontrol karena merasa tidak ada keluhan, susah mencegah semua yang suka makanan bersantan serta kebiasaan makan gorengan. Menurut Mubarak, Chayatin, \& Santoso (2010) Fungsi utama keluarga salah satu diantaranya adalah fungsi perawatan keluarga, dimana keluarga melaksanakan tugas perawatan kesehatan yang bersifat preventif dan secara bersama-sama merawat anggota keluarga yang sakit. Kesanggupan keluarga melaksanakan perawatan atau pemeliharaan kesehatan dapat dilihat dari tugas kesehatan keluarga yang dilaksanakan. Keluarga berfungsi untuk mempertahankan keadaan kesehatan anggota keluarganya agar tetap memiliki produktifitas tinggi. Selain itu tugas keluarga dalam bidang kesehatan adalah kemampuan mengenal masalah kesehatan, kemampuan

Pengambilan sebuah keputusan kesehatan oleh keluarga merupakan langkah sejauh mana keluarga mengerti mengenai sifat dan luasnya masalah, apakah masalah dirasakan, menyerah terhadap masalah yang dihadapi, takut akan akibat tindakan penyakit, mempunyai sikap negatif terhadap masalah kesehatan. Kemampuan 
keluarga dalam mengambil keputusan terhadap anggota keluarga dengan hipertensi mengerti penanganan segera terhadap keluhan gejala hipertensi, menentukan pola makan, pola aktifitas rutin dan menghentikan kebiasaan merokok pada lansia. Pada pengabdian masyarakat peserta belum mengenal masalah kesehatan keluarga dengan optimal. Hal ini diketahui dari hasil apersepsi kegemukan dan makan makanan yang asin penyebab tekanan darah tinggi, sehingga keluarga belum mampu mengambil keputusan dalam merawat anggota keluarga dengan hipertensi maupun yang beresiko hipertensi. Hal ini terlihat pada belum mampu membawa penderita secara rutin kontrol di pelayanan kesehatan. Pada saat penyuluhan keluarga belum mengetahui Bagaimana cara keluarga merubah kebiasaan makan penderita hipertensi yang tidak sehat seperti suka makanan bersantan, makan gorengan saat sarapan atau sore hari. kebiasaan mereka makan obat jika tekanan darah tinggi dan kepala pusing saja. Perseposi masyarakat ini sejalan dengan Penelitian Koyongian (2015) tentang Hubungan peran keluarga dengan kepatuhan berobat pasien hipertensi di desa Batu Kecamatan Likupang Selatan kabupaten Minahasa Utara, diketahui terdapat hubungan yang signifikan antara pelaksanaan fungsi perawatan kesehatan keluarga dengan kepatuhan berobat pasien hipertensi ( $p$ value : 0,000 ).

Pendekatan keluarga adalah salah satu cara Puskesmas untuk meningkatkan jangkauan sasaran mendekatkan/meningkatkan dan pelayanan kesehatan di wilayah kerjanya dengan mendatangi keluarga. Puskesmas tidak hanya menyelenggarakan pelayanan kesehatan di dalam gedung, melainkan juga keluar gedung dengan mengunjungi keluarga di wilayah kerjanya. Konsep pendekatan keluarga adalah salah satu cara Puskesmas untuk meningkatkan jangkauan sasaran dan mendekatkan/meningkatkan akses pelayanan kesehatan di wilayah kerjanya dengan mendatangi keluarga. Puskesmas tidak hanya menyelenggarakan pelayanan kesehatan di dalam gedung, melainkan juga keluar gedung dengan mengunjungi keluarga di wilayah kerjanya. Keluarga sebagai fokus dalam pendekatan pelaksanaan program Indonesia Sehat karena menurut Friedman (2010), terdapat Lima fungsi keluarga, yaitu: 1. Fungsi afektif (The Affective Function) 2. Fungsi sosialisasi yaitu proses 3 . Fungsi reproduksi (The Reproduction Function) 4. Fungsi ekonomi (The Economic Function) 5. Fungsi perawatan atau pemeliharaan kesehatan (The Health Care Function)

$$
\text { Upaya kesehatan berbasis }
$$

masyarakat merupakan salah satu bentuk pelayanan kesehatan di Puskesmas, termasuk upaya pembinaan kesehatan keluarga. Peran perawat komunitas di Puskesmas Paal V dapat dilakukan dengan pendekatan Progran Indonesia Ssehat dengan Pendekatan Keluarga (PIS-PK). Hasil dari PIS-PK salah satunya dapat mengidentifikasi keluarga dengan masalah penyakit-penyakit kronis dan degeneratif seperti hipertensi yang perlu dibina dan dipantau kesehatannya, Perawat dapat membantu keluarga untuk menyelesaikan masalah kesehatan dengan cara meningkatkan kesanggupan keluarga melakukan fungsi dan tugas perawatan kesehatan keluarga. Peran perawat dalam membantu keluarga dengan anggota keluarga menderita hipertensi seperti : memberikan pendidikan kesehatan kepada keluarga agar dapat melakukan perawatan secara mandiri sesuai kemampuan mereka, perawat dapat berperan sebagai koordinator untuk mengatur program kegiatan keperawatan keluarga untuk mempertahankan status kesehatan penderita hipertensi melalui kerjasama lintas program seperti : penyuluhan yang bekerjasama dengan program promosi 
kesehatan, mengkoordinir pengobatan yang teratur dan berkesinambungan pada saat kontrol ulang di Puskesmas Paal V. Sebagai pengawas kesehatan, perawat dapat memantau status kesehatan pasien hipertensi bekerjasama dengan program kesehatan masyarakat dan menjadikan keluarga pasien hipertensi tersebut sebagai keluargaa binaan

\section{KESIMPULAN DAN SARAN}

\section{Kesimpulan}

a. Peserta penyuluhan sebagai anggota keluarga dengan hipertensi maupun beresiko mampu mengenal masalah kesehatan : penyakit hipertensi, Keluarga mampu mengambil keputusan tindakan kesehatan yang tepat dalam merawat anggota keluarga yang menderita atau beresiko mengalami hipertensi, Keluarga mampu memberi perawatan pada anggota keluarga yang menderita hipertensi, Keluarga mampu memodifikasi lingkungan/rumah yang sehat bagi penderita hipertensi dan keluarga mampu menggunakan fasilitas kesehatan yang ada dimasyarakat.

b. Adanya peningkatan pengetahuan peserta penyuluhan tentang optimalisasi tugas keluarga merawat penderita hipertensi sebelum dan sesudah penyuluhan. Peningkatan pengetahuan terjadi setelah penyuluhan kesehatan. Hasil ini menunjukkan bahwa penyuluhan kesehatan yang dilakukan melalui komunikasi informasi edukasi yang menggunakan audio visual semakin memperkuat pemahaman yang ada pada keluarga.

c. Pelaksanaan Program Indonesia Sehat dengan Pendekatan Keluarga di Puskesmas Paal V telah dilaksanakan, salah satunya dapat mengidentifikasi keluarga dengan masalah penyakit- penyakit kronis dan degeneratif seperti hipertensi yang perlu dibina dan dipantau kesehatannya.

\section{SARAN}

a. Agar Puskesmas Pall V dapat menindaklanjuti hasil dengan Pendekatan Keluarga (PIS-PK) menjadikan keluarga pasien hipertensi tersebut sebagai keluargaa binaan, bekerjasama dengan program promosi kesehatan melakukan edukasi dan program penyakit tidak menular untuk kontrol tekanan darah dan pengobatan yang teratur.

b. Membina kerjasama dengan institusi Perguruan Tinggi terutama Perguruan Tinggi kesehatan khususnya Poltekkes Kemenkes Jambi sebagai mitra melalui kegiatan Tridarma Perguruan Tinggi sehingga dapat menciptakan generasi muda yang sehat dan cerdas.

\section{UCAPAN TERIMAKASIH}

Terima kasih penulis sampaikan kepada Direktur Poltekkes Kemenkes Jambi yang telah memfasilitasi izin dan pendanaan kegiatan pengabdian masyarakat ini.

\section{DAFTAR PUSTAKA}

Friedman, M. (2010). Buku Ajar Keperawatan Keluarga : Riset, Teori Dan Praktek Edisi 5. Jakata : EGC.

Kemenkes RI (2017) Program Indonesia Sehat dengan Pendekatan Keluarga

http://www.depkes.go.id/article/view/progr am-indonesia-sehat-denganpendekatan-keluarga.html, diundul tanggal 13 Juli 2019

Koyongian (2015). Hubungan Peran Keluarga Dengan Kepatuhan berobat Pasien Hipertensi Di Desa Batu 
Kecamatan Likupang Selatan Kbupaten Minahasa Utara. E-Journal Keperawatan (eKp) volume 3 Nomor 3 Agustus 2015.

Mubarak, W.I., Chayatin, N., Santoso, B.A. (2010). Ilmu Keperawatan Komunitas Konsep dan Aplikasi, Buku 2, Jakarta: Salemba Medika.

Notoatmodjo. (2010). Promosi Kesehatan Teori Dan Aplikasi. Edisi Revisi. Jakarta: PT. Rineka Cipta.

PERKI, (2015), Pedoman Tatalaksana Hipertensi Pada Penyakit Kardiovaskular Edisi Pertama. Jakarta: PP-PERKI.

Price S.A dan Wilson L.M. (2006). Patofisiologi Proses-proses Penyakit Edisi 6 Volume 1. Penerjemah : Peter Anugrah. Jakarta: EGC.

Riskesdas, (2013). Laporan Hasil Riset Kesehatan Dasar Riskesdas Nasional. Jakarta: Depkes RI http://www.depkes.go.id/resources/do wnload/general/Hasil\%20Riskesda. Diakses tanggal 5 Maret 2019

Smeltzer S.C, Bare B.G. (2002). Keperawatan Medikal Bedah Brunner Dan Suddarth Edisi 8 Volume 2. EGC, Jakarta.

Stanhope, M., \& Lancaster, J. (2004). Community And Public Health Nursing. St. Louis Missouri : Mosby.

Tedjakusuma, P. (2012). Tatalaksana Hipertensi, Cermin Dunia Kedokteran.

WHO, (2013). A Global Brief On Hypertension Silent killer, Global Public Health Crisis. Tersedia dalam http://www.who.int/cardiovascular_di seases/publications/ [Diakses

14 